\title{
Distocia em Pequenos Animais: Causas, Diagnóstico e Tratamento - Revisão
}

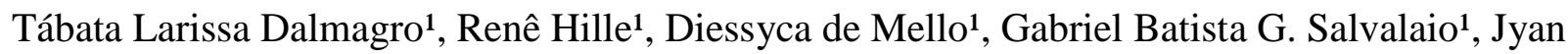
Lucas Benevenute ${ }^{1}$, Raphael Augusto Baldissera Gonçalves ${ }^{1}$

${ }^{1}$ Universidade Estadual do Centro-Oeste, Campus CEDETEG, Departamento de Medicina Veterinária, Guarapuava, Paraná. [dalmagroo@ hotmail.com]

ISSUE DOI: $10.3738 / 1982.2278 .1129$

A distocia é a incapacidade da fêmea gestante em expulsar os fetos durante o trabalho de parto, sendo considerada uma urgência reprodutiva, colocando em risco a vida da gestante e dos fetos. Com o grande aumento nos atendimentos desse tipo de complicação da gestação, é necessário termos conhecimento de como ocorre a distocia e quais são seus possíveis tratamentos. As causas podem estar relacionadas à mãe a ao feto, sendo mais comum o mau posicionamento fetal, impedindo que as contrações expulsem os fetos. Entre outras causas de distocias, existem ainda a desproporção feto-pélvica, obstrução das vias fetais, seja por deformidades da pelve ou vias fetais moles, torção e inércia uterina. O diagnóstico da distocia pode ser realizada por palpação abdominal e exame digital vaginal, sendo que os métodos mais confiáveis são a ultrassonografia e radiografia. O tratamento da distocia em pequenos animais pode ser medicamentoso ou manipulativo, porém somente é feito quando a fêmea apresenta boas condições clínicas, dilatação do canal do parto, com fetos em tamanho proporcional ao diâmetro desse canal e estática fetal adequada. O tratamento cirúrgico é empregado nos casos em que a correção da estática fetal não é possível clinicamente e quando o uso de fármacos não resulta em contrações produtivas. Nesse caso, a cesariana é a única forma de salvar os filhotes. Esta intervenção deve ser realizada antes que ocorra fadiga da fêmea em trabalho de parto ou sofrimento fetal. Está indicada para pacientes com parto excessivamente longo, sinais de endotoxemia ou septicemia, em casos de morte fetal com putrefação, ou quando há antecedentes de distocia. A distocia ocorre geralmente quando não há um acompanhamento pré-natal em cadelas e gatas. Portanto é indicado que sejam realizados exames durante a gestação para prevenir situações que envolvam a necessidade de auxílio ao parto ou cesariana. Tomando essas decisões pode-se prevenir essas, bem como outras complicações, e obter sucesso em salvar a mãe e os fetos.

Palavras-chave: distocia, causas, diagnóstico, tratamento, prevenção 